\title{
Calculation Method of Overburden Damage Height Based on Fracture Mechanics Analysis of Soft and Hard Rock Layers
}

\author{
Liang Chen $\mathbb{D}^{1,2,3}$ Shaowu Fan, ${ }^{1,3}$ Can Zhao, ${ }^{1,3}$ Lang Zhang, ${ }^{1,3}$ and Zhiheng Cheng ${ }^{1,3}$ \\ ${ }^{1}$ Mine Safety Technology Branch of China Coal Research Institute, Beijing, China \\ ${ }^{2}$ Faculty of Resource \& Safety Engineering, China University of Mining and Technology Beijing, Beijing, China \\ ${ }^{3}$ State Key Laboratory of Coal Mining and Clean Utilization (China Coal Research Institute), Beijing, China
}

Correspondence should be addressed to Liang Chen; 171753953@qq.com

Received 6 July 2018; Accepted 18 October 2018; Published 27 February 2019

Guest Editor: Wen Wang

Copyright (c) 2019 Liang Chen et al. This is an open access article distributed under the Creative Commons Attribution License, which permits unrestricted use, distribution, and reproduction in any medium, provided the original work is properly cited.

Under the geological condition of soft and hard rock interaction stratum, the overburden damage height can provide a quantitative support for the design of the locations of gas drainage boreholes in the roof mining fracture zone and the determination of the hydraulic fracture zone in coal seam mining. The interbedded structure of overlying mud rock and sandstone in the Lu'an mining area in Shanxi is a typical soft and hard rock interaction stratum. In view of the lack of soft rock fracture mechanics analysis and the improper calculation of the damage height of overburden rock caused by constant rock residual bulking coefficient to be used regularly in the analysis, in this paper, we constructed a fracture model of soft and hard strata by giving a quantitative classification criterion of soft and hard rocks and introducing a fracture failure criterion of soft rock strata and the space constraint condition of broken-expansion rock formation. Aiming at improving the calculation precision of overburden damage height, we presented a calculation method based on fracture mechanics analysis of soft and hard strata, which could delineate the extent of intact rock in overlying strata from bottom to top to determine the damage height of overburden rock. This research took Yuwu coal mine in Lu'an mining area as an example. Results showed that (1) by the calculation method, the overburden damage height of the N1102 fully mechanized caving face in Yuwu coal mine was $51.44 \mathrm{~m}$, which was less than the value obtained by an actual borehole TV method as well as the numerical simulation result of $53.46 \mathrm{~m}$, with a calculation accuracy about $96.22 \%$, which is quite high for both. The calculation accuracy of the proposed method was higher than that of the three conventional theoretical methods, and it effectively solved the limitation of the fracture analysis method without the inclusion of the soft rock layer in design and the distortion problem due to the residual bulking coefficient to be improperly used in simulation. (2) There was no noticeable fractures in the broken soft rock zone, and the whole fractures were mainly low-angle rupture; the fractures in hard rock layer had obvious ruptures and multiangle cracks, and the average fracture width of soft rock was $2.8 \mathrm{~mm}$ smaller than that of hard rock. The fracture modes of soft rock and hard rock were mainly tensile failure and tensile shear failure, which verified the correctness of the fracture mechanics model of soft and hard rock layers constructed in this paper. (3) It is noticed that the tensile strength of rock in this method needs to be obtained through rock mechanics experiment on overlying strata in the study area, and our proposed method was applicable to the mining conditions of near horizontal coal seam. The calculation accuracy of this method meets the engineering error requirements and can be applied to the prediction of overburden damage height in near horizontal coal seam mining.

\section{Introduction}

In the mining activities of a shaft, the overlying strata of the coal body will be broken and bent and sunk by the pressure of the mine. The fractures and fissures will occur along the longitudinal and lateral directions of the coal (rock) layer, and these fissures and fractures will form a gas and water channel, leading to the working face gas to increase or induce the roof water inrush accident. Therefore, determining the height of overburden damage in coal seam mining is of great significance to the prevention of mine water inrush accidents and the efficient extraction of gas in goaf [1].

Scholars from various countries have proposed a variety of theories to study the height of overburden damage. As 
early as the mid-19th century, Adhikary and Guo proposed the vertical line theory to describe the movement of overburden deformation [2]. Kayabasi et al. proposed an influence function model to characterize the overburden failure feature [3] by studying the mining area and zoning. Singh et al. first proposed the "three-band" theory (falling zone, fracture zone, and continuous deformation zone) and used the equivalent mining height method to give the multiple relationship between the "three-band height" and the mining height [4]. Álvarez et al. proposed the "four-band" theory (falling zone, fracture zone, composite beam structure zone, and surface) through further refinement research and gave the empirical value [5] of the "four-belt" height. Liu introduced the "three-band" empirical formula [6] to calculate the overburden damage by statistically examined the measured date in the field of Huabei mining area and combined with elastoplastic mechanics and then wrote it into the "Procedure of Main Shaft Coal Pillar Retention and Coal Mining under Buildings, Water Bodies and Railways" (hereinafter referred to as "three down" procedures) [7]. Since then, the "three-band" theory has been widely used in the study of mining overburden damage height. In recent years, relevant scholars have conducted in-depth research based on the fracture angle, shape, and structure of rock formation. Qian et al., Xu et al., and Zuo et al. analyzed the formation of masonry beam structure to model the breaking of the overburden rock stratum and then proposed the key layer theory and calculated the damage height of mining overburden by their proposed method [8-10]. Singh and Singh and Abbas et al. simplified the two-dimensional overburden failure formation to a paraboloid or a triangle and gave a functional relationship between the damage height and the mining height $[11,12]$. Li et al. simplified the three-dimensional overburden failure formation into an elliptical belt and gave the mathematical expression [13] of its damage height and mining height, working surface size, and other factors. $\mathrm{Xu}$ et al. proposed the calculation formula for the failure height of mining overburden using the critical value of the fracture angular displacement in case the rock stratum is broken [14]. In addition, Ozgen and Gerrit and $\mathrm{Hu}$ et al. established a multifactor comprehensive calculation model [15] for overburden damage height by analyzing the factors such as slope length of working face, mining height, cover depth, lithology, and propulsion speed. Minghe et al. analyzed the influence of sandstone grain size on the failure height of overburden by physical model test and proposed the calculation model of fracture zone height in compacted mode and cemented mode [16]. Sui et al. researched the height of overburden damage caused by superimposed mining in multiple coal seams, and Zhao et al. proposed the calculation formula for the fractured zone of overlying strata under superimposed mining $[17,18])$.

The calculation models of the above-mentioned overburden damage height are mostly based on the study of hard rock strata, in which they were considered that the bearing key layer determines the overburden damage height [19], and there was few studies on soft rock deformation and damage, which will lead to the miscalculation, especially under the conditions of interactive stratum of soft and hard rock interactive stratum where soft rock has a greater impact on the damage of mining overburden. Soft rock has a certain inhibitory effect on the development of overburden damage because it has low failure strength, can have a significant plastic deformation, and easy to be compacted after failure. When the soft rock is at a relatively high level from the coal seam, the inhibition effect is obvious [20]. Du and Bai proposed a stress arch model by analyzing the failure structure and formation of the thick and soft rock overburden and pointed out that it determined the damage height [21] of mining overburden. Mandal et al., Rafiqul et al., and Vishal et al. established a finite element model [22-24] for the simulation of soft rock overburden failure by analyzing the failure formation, structure, and mechanical properties of soft rock overburden. Such group of calculation models based on the fracture structure of soft rock and its mechanical properties usually needs to analyze and determine the fracture structure and formation of soft rock overburden. These parameters are complex and difficult to obtain, and many parameters in the calculation models (the mining stress attenuation coefficient and the proportion of overlying soft rock) were obtained by semiempirical model calculation [25], so it has strong limitations.

In addition, the height of the overburden failure zone is closely related to the collapse characteristics of the broken rock stratum [26]. The characteristics of the residual fragmentation of the rock stratum under a process of breaking and compressing determine the size of the bulking space of the broken overburden and then control the progressive height of the overburden fault. It is the key influencing factor. At present, there are two concerns in the application of the residual crack expansion coefficient of rock to calculate the height of the bulking space under the overburden. First, it is to select the initial coefficient of expansion of the broken rock [27], with less consideration to be given to the crushed compaction of the overlying rock mass. Secondly, the initial coefficient of expansion of the broken rock under constant pressure was rarely analyzed [28]. And it neglected the influence of different broken rock mass and varied compressive stresses on the residual crack expansion coefficient during the process of failure-slipping-compaction of the overburden. This leads to a deviation in the height calculation result.

Aiming at the issues of noninvolvement of soft rock fracture mechanics and the improper calculation of overburden failure height caused by constant rock residual crack expansion coefficient, this paper introduced the quantitative criterion of soft and hard rock and introduced the soft rock stratum mechanical criterion. Based on the influencing factors of residual broken-expanding dynamic characteristics of rock stratum after failure, it defined the spatial constraints of overburden fracture induced by pressure release of mining and the fracture models of soft and hard rock layers were constructed to determine the location of unidentified fractures in overburden and improve the calculation accuracy of overburden failure height. The calculation was examined by Yuwu coal mine in Lu'an mining area, and its accuracy was well verified by the field test results. 


\section{Methods}

Generally, the lithologic structure of the overlying strata of the coal seam has many interactions between soft and hard rock layers, not a single hard rock structure or soft rock structure. Secondly, the bearing key layer (hard rock) has an important influence on the height of overburden damage. Due to different lithologies, the residual bulking characteristics of the rock stratum after breaking and compressing directly affect the tapered law of the downward bulking space of the broken rock strata after coal seam mining and then determine the ultimate damage height of the overburden. Therefore, the fracture mechanical conditions of soft and hard rock layers and their residual bulking characteristics are the key to the damage height of overburden failure.

In order to solve the problem of the lack of soft rock fracture mechanics analysis and the inaccurate calculation of overburden damage height incurred by constant rock residual bulking coefficient, this paper introduced the quantitative criterion of soft and hard rock and introduced the soft rock stratum mechanical criterion and the space constraints of expansion of the broken rock stratum. A calculation method of overburden damage height based on fracture mechanics analysis of soft and hard rock layers was proposed, and theoretical analysis and calculation of overburden damage height are carried out.

\subsection{Quantitative Criteria for Soft and Hard Rock Formations.} The lithologic structure of overlying strata directly affects the mechanical strength, failure mode, and residual bulking characteristics of rock stratum. Xu and Qian pointed out that tensile strength was an important mechanical parameter for judging the development of fractures [29]; Xie et al. believed that hard rock was mainly characterized by brittle failure under mining conditions whereas the soft rock was characterized by plastic failure [30]. In summary, in view of the difference of fracture strength, fracture mode, and residual bulking characteristics between soft and hard rock layers, it is necessary to classify and analyze the overburden. Therefore, this paper combined the saturated uniaxial compressive strength of soft and hard rock in the engineering rock mass classification standard [31] to give the criterion of soft and hard rock classification from the two aspects of bearing capacity and failure mode of rock stratum: hard rock compressive strength $\sigma_{c} \geq 30 \mathrm{MPa}$, whose full stress-strain curve shows obvious postpeak stress drop instantaneously, and the compressive strength of soft rock is $\sigma_{c}<30 \mathrm{MPa}$, whose full stress-strain curve does not show obvious postpeak stress drop but decreases slowly and has obvious timeliness.

\subsection{Stress Analysis of Soft and Hard Rock Layers during Breaking}

\subsubsection{Stress Analysis of Hard Rock Formation under Mining Conditions}

(1) Judgment of the Bearing Layer. Since the thicker hard rock layer plays a role in supporting the overburden, the thinner soft rock layer only acts as a load, the overlying rock stratum between adjacent key layers is simplified into a composite beam model, and the load of the first layer of hard rock [29] is

$$
\left.q_{1}(x)\right|_{m}=\frac{E_{1} h_{1}^{3} \sum_{i=1}^{m} \gamma_{i} h_{i}}{\sum_{i=1}^{m} E_{i} h_{i}^{3}}
$$

When the $m+1$ th layer is a hard rock, that is, it is not the same composite beam as the following $m$ layer, for the first layer, there is

$$
\left.q_{1}(x)\right|_{m}>\left.q_{1}(x)\right|_{m+1} .
$$

The bearing layer contained in the rock layers between two adjacent key layers is sequentially determined by the above formula.

(2) Mechanical Conditions of Hard Rock Fracture. The hard rock fracture condition is that the load $q$ exceeds its own tensile strength and the simple supported beam model can be used to derive the following formula:

$$
\sigma_{\max }=\frac{q l^{2}}{2 h^{2}}>\sigma_{t} .
$$

The corresponding hard rock fracture step [32] is

$$
l_{H}=h \sqrt{\frac{2 \sigma_{t}}{q}} .
$$

Due to the bulking property of the rock stratum after breaking, the space beneath the overburden rock is getting smaller and smaller as the rock layer breaks from the bottom to the top (see Figure 1), which satisfies the following formula.

$$
\Delta_{i}=M-\sum_{j=1}^{i-1} h_{j}\left(k_{p j}^{\prime}-1\right) .
$$

The critical mining length [32] of the $j$-th story fracture in the overburden is

$$
L_{j}=\sum_{i=1}^{m} h_{i} \cot \varphi_{a}+l_{j}+\sum_{i=1}^{m} h_{i} \cot \varphi_{b} .
$$

Therefore, when the working surface advancement length is greater than the corresponding critical mining length of the hard rock formation and there is a space for bulking below the hard rock formation, that is, formula (7) is satisfied, the hard rock of the layer is broken.

$$
\left\{\begin{array}{l}
L_{j}>h \sqrt{\frac{2 \sigma_{t}}{q}}, \\
M-\sum_{j=1}^{i-1} h_{j}\left(k_{p j}^{\prime}-1\right)>0 .
\end{array}\right.
$$




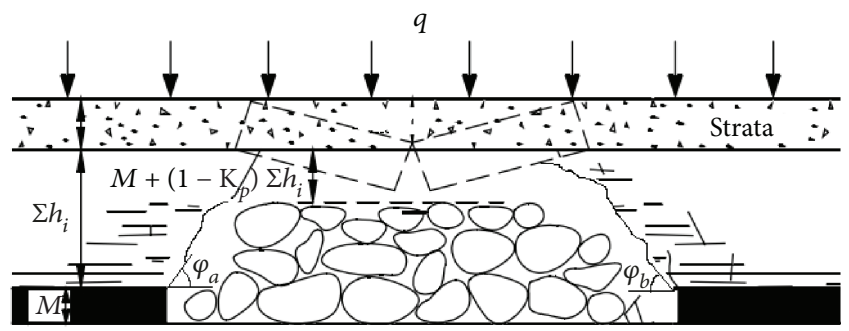

Figure 1: A diagram of fragmentation space under the rock.

2.2.2. Stress Analysis of Soft Rock Formation under Mining Conditions. Based on the plate and beam theory [33] in elastic mechanics, the fracture mechanics condition of soft rock layer is that the horizontal tensile strain generated under load exceeds the ultimate tensile strain, as shown in the following equation:

$$
\varepsilon_{\max }=\frac{3 q l^{2}}{8 E h^{2}}>\frac{\sigma_{t}}{E} .
$$

The fracture step of the corresponding soft rock formation is

$$
l_{S}=h \sqrt{\frac{8 \sigma_{t}}{3 q}} .
$$

The maximum deflection of soft rock is

$$
\omega=\frac{5 q l^{4}}{32 E h^{3}} .
$$

When a soft rock layer breaks, it must meet the horizontal tensile strain generated by the load to be greater than its ultimate tensile strain and the corresponding deflection of the soft rock is less than the height of the small expansion space below it, as shown in the following equation:

$$
\left\{\begin{array}{l}
\frac{3 q l^{2}}{8 E h^{2}}>\frac{\sigma_{t}}{E}, \\
\frac{5 q l^{4}}{32 E h^{3}}<M-\sum_{j=1}^{i-1} h_{j}\left(k_{p j}^{\prime}-1\right) .
\end{array}\right.
$$

2.2.3. Calculation of Residual Bulk Expansion Coefficient after Rock Stratum Breaking. The residual bulk expansion coefficient of the broken rock stratum changes dynamically with the failure process of the overlying strata and is related to the rock strength, the fracture block, and the compressive stress. In recent years, $\mathrm{Su}$ et al. proposed that the initial coefficient of bulk expansion of fractured rock $K_{p 0}$ is exponentially related to the blockiness $x$, considering the influence coefficient $b$ of the overburden lithology, which satisfies formula (12) [34], and the degree of compaction is considered by experimental research (ratio of residual
TABLE 1: Parameter value table for the calculation formula of residual expansion coefficient as mudstone and sandstone rock breaking.

\begin{tabular}{lcccc}
\hline Lithology & $A$ & $B$ & $C$ & $D$ \\
\hline Mudstone & 0.17 & 0.32 & -0.51 & 1.36 \\
Sandstone & 0.12 & 0.45 & -0.37 & 2.21 \\
\hline
\end{tabular}

coefficient of rock expansion of $K_{p}{ }^{\prime}$ to its initial coefficient of bulk expansion coefficient $K_{p 0}$ ) and satisfy an exponential function relationship with the compressive stress $\sigma[35,36]$, as shown in equation (13). Taking into account the influence coefficient $d$ of rock strength, based on the ground stress $\sigma$ and buried rock, the relationship between deep $H$ and $\sigma$ could be seen in equation (14) [8]. In order to avoid the direct use of a constant bulking coefficient, which lead to a calculation result of overburden damage height too small, in this paper it comprehensively considered compressive stress, rock tensile strength, and fracture block to characterize the residual bulking coefficient after the fracture of the mud and sandstone layer in the overburden. The dynamic information of the bulking coefficient can improve the calculation accuracy of the lower space of the bulking space when the overburden strata are broken. Integrating equations (12), (13), and (14), it can be used to obtain the mathematical relationship between residual bulking coefficient, compressive stress, fractured rock mass, and strength after fracture of rock formation. Equation (15) further simplifies the available formula (16), where $A, B$, and $C$ are formula coefficients and $D$ is the correction coefficient related to the lithology and strength of overburden strata.

$$
\begin{aligned}
K_{p 0}= & a \ln x+b, \\
K_{p}^{\prime} / K_{p 0}= & c \ln \sigma+d, \\
s= & 0.027 H, \\
K_{p}{ }^{\prime}= & a c \ln (x+0.027 H)+a d \ln x \\
& +b c \ln 0.027 H+b d, \\
K_{p}{ }^{\prime}= & A \ln (x+0.027 H)+B \ln x \\
& +C \ln 0.027 H+D .
\end{aligned}
$$

Based on Su et al.'s compaction experimental data [34] of fractured mudstone and sandstone, it can be concluded that when the lithology of an overburden rock is mudstone or sandstone, the corresponding parameters in equation (16) are as shown in Table 1.

2.3. Method for Determining the Height of Overburden Damage. The step to determine the overburden damage height can be divided into the following three steps, as shown in Figure 2:

(1) Identify all of the key layers present in the overlying rock based on the key layer theory. The key layer is the bearing body of the overburden, which plays an 


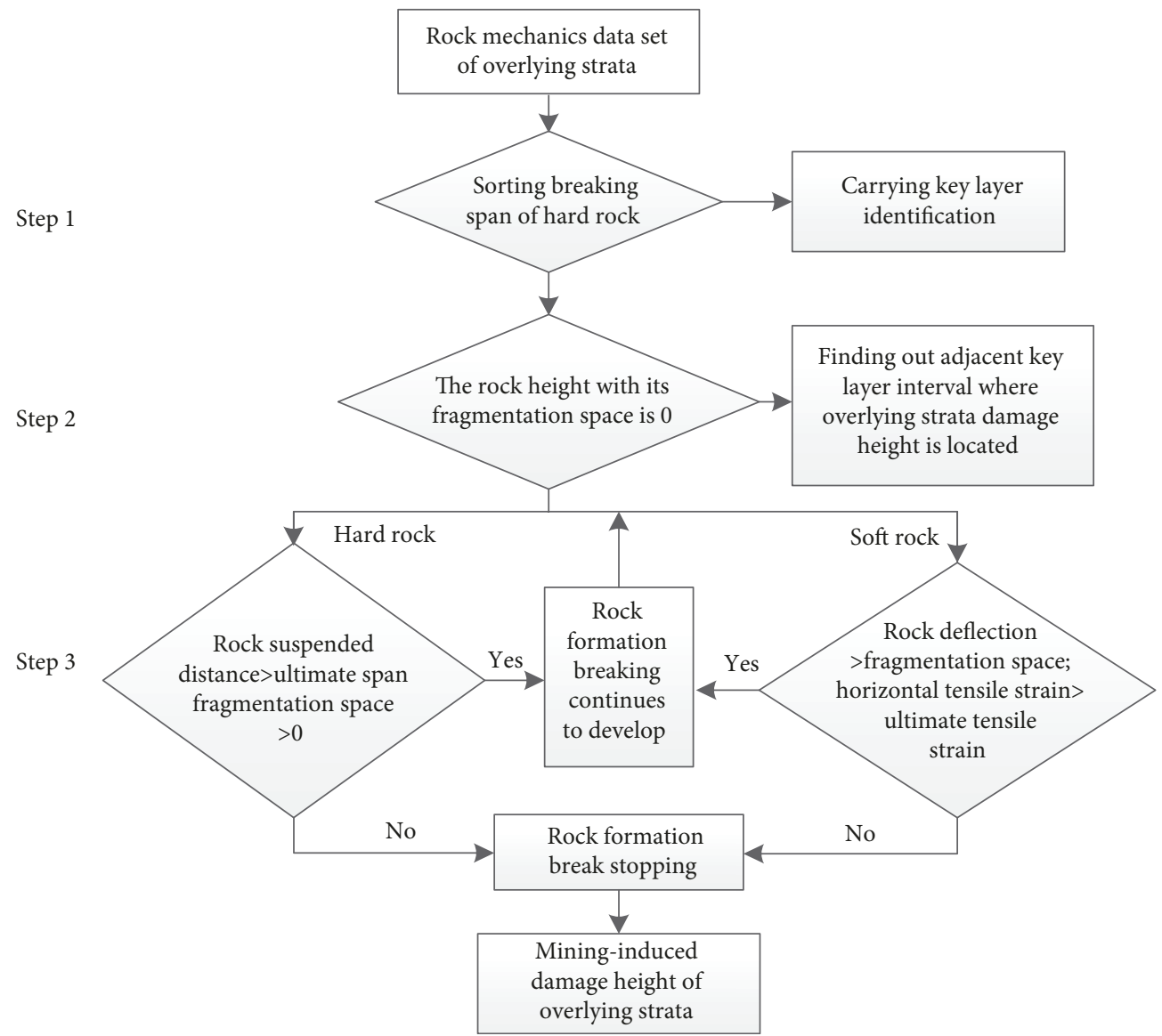

FIGURE 2: Decision process of mining-induced damage height of overlying strata.

important role in the development and extension of the mining fracture, and can provide a basis for judging the approximate interval of the development of the height of fracture

(2) According to the calculation formula (16) of the residual bulking coefficient of fractured rock strata in this paper, based on the coal seam mining height and the residual bulking coefficient of each rock stratum, the height value of the rock mass is retrieved as the height of bulking space beneath the overburden is 0 . The adjacent upper and lower key layers are preliminarily located, where it is critical threshold

(3) After the interval between the adjacent two key strata is determined, according to the fracture mechanics conditions of the soft and hard rock layers and the height of the down-bulking space beneath the rock stratum, the fractures of soft and hard rock layers in each rock stratum between adjacent key layers were further examined. When the hard rock stratum suspension distance is greater than the fracture step distance, there would exist a small bulking space in the lower part. The hard rock layer breaks, and the fracture continues to develop upward; when the soft rock is loaded, in case that the horizontal tensile strain is greater than its ultimate tensile strain, and the corresponding deflection is less than the height of the bulking space beneath the soft rock layer, the soft rock layer breaks and the fracture continues to develop. Otherwise, the fracture development stops. According to this, the layer is analyzed upward to find the rock layer that has not broken. The height of the rock layer from the roof of the coal seam is the height of the overburden damage

\section{Case Analysis and Verification}

3.1. Calculation of Overburden Damage Height in the Study Area. Yu'an coal mine is located in the southwest of Changzhi City, Shanxi Province (Figure 3), north latitude $\mathrm{N} 36^{\circ} 22^{\prime} 39.82^{\prime \prime}$ and east longitude E1 $12^{\circ} 50^{\prime} 78.95^{\prime \prime}$. The main coal seam of Yuwu coal mine was the no. 3 coal seam of the Permian Shanxi Formation, with an average thickness of $6.3 \mathrm{~m}$ and a dip angle of $4^{\circ}$. The N1102 working face had a tendency length of $280 \mathrm{~m}$ and a strike length of $1078 \mathrm{~m}$ (Figure 4). Adopting the fully mechanized top coal caving method, the working face was $3 \mathrm{~m}$ high and the coal caving thickness was $3.3 \mathrm{~m}$. The working surface was arranged to go to the long arm of coal mining. The buried depth of the coal seam roof of the working face was $400-460 \mathrm{~m}$.

A hard rock K8 sandstone with a thickness of more than $40 \mathrm{~m}$ was developed in the area above the coal seam roof above the m1102 working face. It can be regarded as the stable upper boundary of the coal seam overburden. Therefore, 


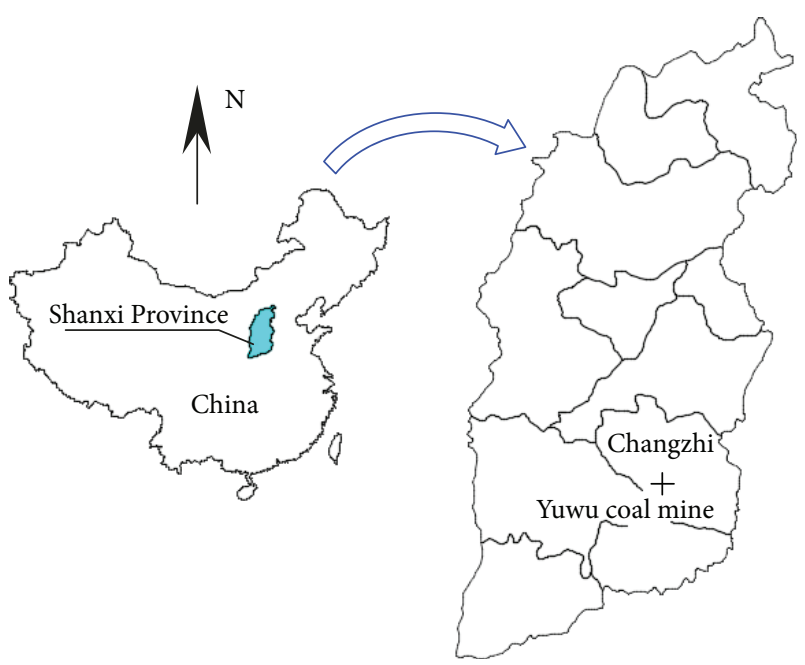

Figure 3: Location of Yuwu coal mine.

the calculation boundary of the key layer was selected to be $133 \mathrm{~m}$ away from the coal seam roof. According to the geological exploration data of the working face, the overlying stratum structure was characterized by mud and sandstone interactive rock layers. According to the experimental results of rock mechanics parameters of the overburden of 3\# coal seam in Yuwu coal mine [37], the thickness of each rock layer and its mechanical parameters are as shown in Table 2.

According to formulas (1), (2), and (3) in the method, it can be concluded that there are 4 key layers in the overburden of $3 \#$ coal seam above the working face (Table 3) and the breaking step size of each key layer is sorted: key layer $4>$ key layer $3>$ key layer $2>$ key layer 1 . Considering the buried depth, fault block, and overburden lithology, the residual bulking coefficients in the overburden after breaking can be obtained from formula (15), which were 1.05, 1.06, $1.08,1.09,1.11$, and 1.18 for mudstone, sandy mudstone, siltstone, fine-grained sandstone, medium-grained sandstone, and coarse-grained sandstone, respectively, and are broken. By formula (5), when the overburden height is $70.8 \mathrm{~m}$, the lower bulking space is zero. Based on this, it was preliminarily judged that the overburden damage height was between the key layer 2 and the key layer 3, that is, 41.11 to $75.33 \mathrm{~m}$.

Because the overburden structure was characterized by mud and sandstone interaction layer, the rock fracture analysis was carried out from the bottom to the top according to the bulking space of the lower part of the rock formation and the fracture conditions of the soft and hard rock layers. According to formula (7), the 15th layer belongs to the hard rock, the breaking step is $36.3 \mathrm{~m}$, and there is a space for the expansion below it, so the rock will break. According to formula (10), it can be seen that the bulking space below the 17 th layer of mudstone is 0 and when the suspended distance of the 16th layer of sandy mudstone is $70 \mathrm{~m}$, the corresponding deflection is $4.1 \mathrm{~m}$, which is greater than the height of the bulking space below the rock formation $0.65 \mathrm{~m}$. Therefore, the 16th and 17th layers of rock will not break. According to the theoretical calculation, with the advancement of working face, the maximum overburden damage height is the height from the 16th layer rock to the roof of the $3 \#$ coal seam, $51.44 \mathrm{~m}$.

3.2. Drilling Test Verification. Drilling TV imaging technology is to directly feed the waterproof camera probe with light source into the borehole, which can truly reflect the rock mass characteristics of the borehole wall. Kang et al., Zhang et al., and Wang et al. applied this technology for the detection of rock structure and rock mass fracture characteristics [38-40]. The borehole TV imaging technology was used to detect the overburden failure characteristics during the N1102 mining process. The type of drilling TV equipment was ZKXG-30 (Figure 5) produced by Tianchen-Weiye Geophysical Technology Co. Ltd. In Wuhan Province of China, the schematic diagram of its working principle is shown in Figure 6. In this study, four oblique drilling boreholes were arranged in the goaf of the working face, as shown in Figure 7. The distance from the cutting lane to drilling boreholes was $150 \mathrm{~m}$, and the borehole depth was not less than $90 \mathrm{~m}$. The construction parameters are shown in Table 4 .

3.2.1. Analysis of Borehole Images. Based on the 2\# borehole endoscopic image, the comparative analysis of the primary fracture before the mining face and the quantitative variation of the fracture of the overburden after mining can provide a basis for determining the height of the overburden damage. As shown in Figure 8(a), in the section of the borehole depth $35 \sim 40 \mathrm{~m}$, the overlying rock fissures before mining are mainly represented by bedding and joints and the number and width of overlying fractures in this section increased significantly after mining. Especially in the range of $36 \sim 39 \mathrm{~m}$, there produced crisscross cracks, which were typical fractured cracks.

In the obtained images of the inner wall of the borehole, the top of the caving zone after coal seam mining can be observed (Figure 9) and then the height of the caving zone was estimated to be $30.1 \sim 33.5 \mathrm{~m}$, but it is necessary to determine the height of the overburden damage before mining. The subsequent fissures were further quantified.

\subsubsection{Determination of the Height of Overburden Damage.} Image-Pro image processing software was used to further analyze the parameters such as the number and width of cracks in the 2\# borehole images for statistical analysis. The analysis process of borehole endoscopic images using Image-Pro software is shown in Figure 10. The number of cracks and the variation of the crack width corresponding to different borehole depth ranges before and after mining were obtained (Table 5). Then two fitting curve equation can be obtained between the number of cracks and the depth $x$ of the borehole before and after the mining (Figure 11). They were $y=0.00006 x^{3}-0.0084 x^{2}+0.3075 x+0.3065$ and $y=0.0003 x^{3}-0.0572 x^{2}+2.5887 x-16.875$, respectively. The former fitting coefficient was $R^{2}=0.5447$, a poor fitting, indicating that the distribution of overlying fractures before mining was not related to the pore depth, but related to its structure; the latter fitting coefficient was $R^{2}=0.9748$, a better fitting. In the borehole depth $<30 \mathrm{~m}$, the number of fractures was proportional to the depth of the borehole and the growth 


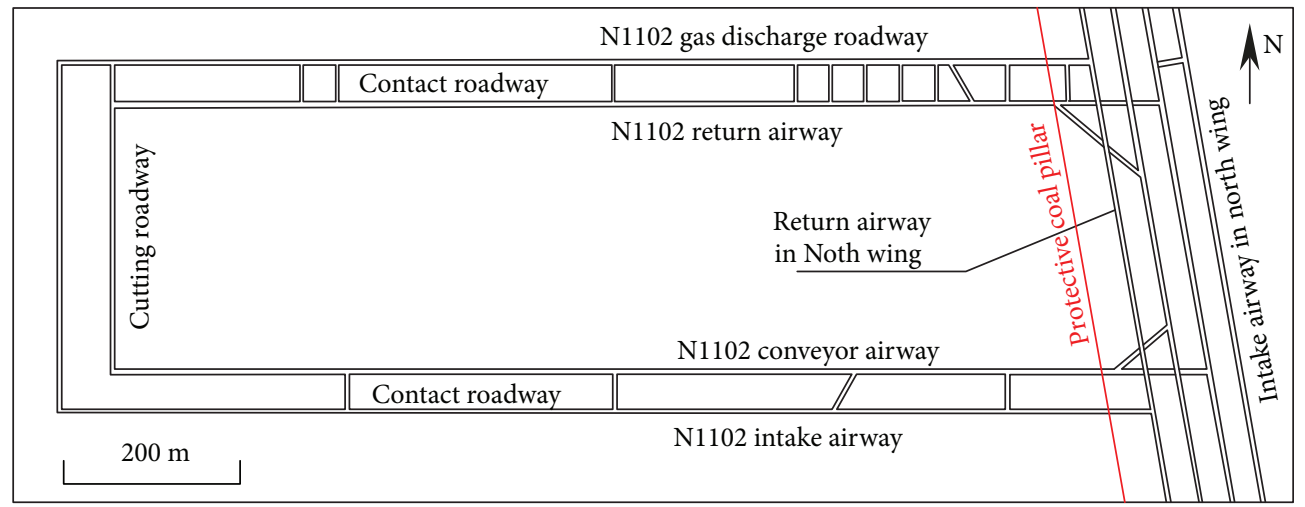

FIGURE 4: Schematic diagram of N1102 working face of Yuwu coal mine.

TABLE 2: Overlying rock thickness and its mechanical parameters of N1102 working face.

\begin{tabular}{|c|c|c|c|c|c|}
\hline Number & Thickness (m) & Rock name & Density $\left(\mathrm{kN} \cdot \mathrm{m}^{-3}\right)$ & Tensile strength (MPa) & Elastic modulus (GPa) \\
\hline 20 & 40.61 & K8 sandstone & 25.31 & 7.87 & 36.01 \\
\hline 19 & 5.3 & Sandy mudstone & 21.64 & 5.61 & 18.35 \\
\hline 18 & 12.56 & Fine sandstone & 26.45 & 8.81 & 36.79 \\
\hline 17 & 4.6 & Mudstone & 25.98 & 1.14 & 18.46 \\
\hline 16 & 9.6 & Sandy mudstone & 23.64 & 5.61 & 18.35 \\
\hline 15 & 3.3 & Siltstone & 25.46 & 5.12 & 24.55 \\
\hline 14 & 0.47 & Coal seam & 10.36 & 1.27 & 4.2 \\
\hline 13 & 4.52 & Sandy mudstone & 26.23 & 5.81 & 18.46 \\
\hline 12 & 3.37 & Coarse sandstone & 25.64 & 5.34 & 21.31 \\
\hline 11 & 10.27 & Fine sandstone & 27.54 & 6.88 & 32.87 \\
\hline 10 & 3.5 & Mudstone & 24.68 & 4.17 & 18.35 \\
\hline 9 & 4.3 & Fine sandstone & 26.73 & 6.14 & 28.33 \\
\hline 8 & 3.2 & Sandy mudstone & 25.98 & 5.81 & 18.46 \\
\hline 7 & 3.58 & Fine sandstone & 26.73 & 6.14 & 29.57 \\
\hline 6 & 3.07 & Siltstone & 25.2 & 3.52 & 24.13 \\
\hline 5 & 3.14 & Mudstone & 23.68 & 1.14 & 18.35 \\
\hline 4 & 3.35 & Siltstone & 25.1 & 4.52 & 23.17 \\
\hline 3 & 3.82 & Fine sandstone & 26.73 & 6.14 & 29.09 \\
\hline 2 & 6.03 & Medium sandstone & 26.82 & 8.11 & 35.62 \\
\hline \multirow[t]{2}{*}{1} & 5.12 & Mudstone & 24.68 & 1.04 & 18.35 \\
\hline & 6.3 & 3\# coal seam & 14.45 & 3.19 & 6.7 \\
\hline
\end{tabular}

TABLE 3: Key layer parameter calculation result.

\begin{tabular}{lccccc}
\hline Number & Lithology & Rock thickness $(\mathrm{m})$ & Key layer number & Breaking span $(\mathrm{m})$ & Height upper coal seam $(\mathrm{m})$ \\
\hline 1 & Medium sandstone & 6.03 & Key layer 1 & 36.3 & 5.12 \\
11 & Fine sandstone & 10.27 & Key layer 2 & 50.3 & 41.11 \\
18 & Fine sandstone & 12.56 & Key layer 3 & 81.4 & 75.33 \\
20 & K8 sandstone & 40.61 & Key layer 4 & 158.9 & 80.54 \\
\hline
\end{tabular}

rate was faster. The reason was that after the coal seam was mined, the compressive stress was higher after the fracture of the overburden rock near the roof of the coal seam and the broken fractures were higher. In the range of borehole depth $30 \sim 40 \mathrm{~m}$, the number of fractures reached the maximum value. This area was the transition zone between the falling zone and the fracture zone, and the fractures were most developed. In the range of borehole depth greater than $40 \mathrm{~m}$, the number of fractures gradually decreases and the deceleration was slower. After the breakage 


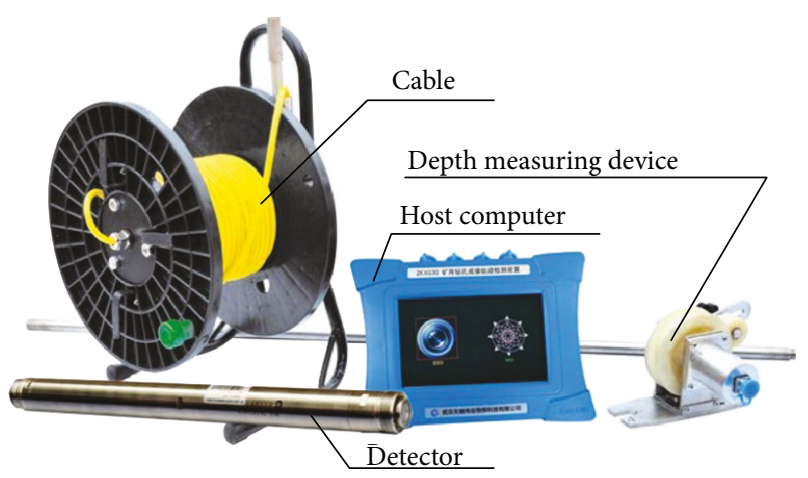

FIGURE 5: ZKXG-30 drilling TV detection equipment.

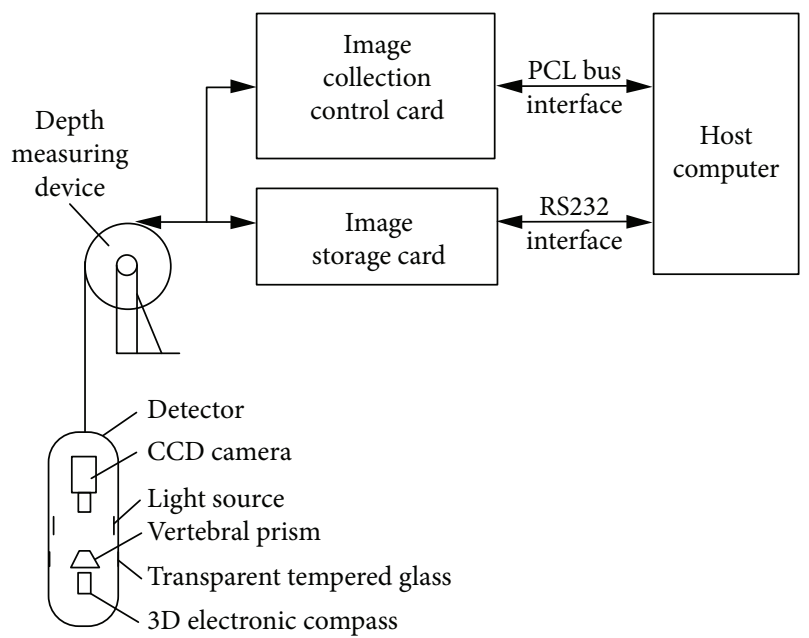

Figure 6: The schematic diagram of the drilling TV equipment's working principle.

of the rock formation, the broken expansion of the upper rock layer shrank, so that the relatively high rock formation will not completely break.

The difference in the number of cracks before and after mining can be considered as cracks which were generated when the overburden damage had occurred. The data obtained were as follows: the depth of the borehole was less than $60 \mathrm{~m}$, and the difference in the number of the cracks before and after the mining of each $10 \mathrm{~m}$ was $>15$, with the maximum 32, referred to a fissure development zone; and the borehole depth was in the range of $60-80 \mathrm{~m}$, and the difference in the number between the prefracture and postfracture was $<5$, which can be regarded as the undeveloped zone of the fissure. Therefore, it is judged that the height of the overburden damage of the working face corresponded to a borehole depth of $60 \mathrm{~m}$. Considering that the drilling angle was $63^{\circ}$, the overburden damage height would be $60 \times \sin$ $63^{\circ}=53.46 \mathrm{~m}$, which is basically consistent with the calculated height with our method.

\subsubsection{Verification of Mechanical Model of Soft and Hard Rock Strata}

(1) Verification of Soft and Hard Rock Fracture Methods. The hard rock failure mode is mainly brittle failure, with the generation of block fractures which are not easy to close, and many high-angle fractures are fully developed with good ductility [41]; the soft rock failure modes are mainly tensile failure, and the fracture structure is pressure sensitive, with fracture gap easy to close. Based on the $3 \#$ borehole detection image, the fracture modes of the soft and hard rock fractures were analyzed to verify the fracture modes.

As shown in Figure 12(a), the soft rock is mainly composed of crisscross fractures and there is no obvious fracture. The compactness is good but poor ductility, and there is fragmentation around the crack, indicating that the soft rock is mainly plastic damage, with strong pressure sensitivity, which is consistent with the failure mode of the soft rock layer proposed in this paper.

As shown in Figure 12(b), the fractures of the hard rock layer are large in size and mainly longitudinal cracks, with good ductility and relatively tidy fracture, and the width is relatively large, which indirectly indicates that the hard rock damage is mainly due to brittle failure. And the fracture gap is not easily compacted, which is consistent with the failure mode of the hard rock layer proposed in this paper.

(2) Constraints of Overburden Fracture and Bulking Space. According to the statistical results about the number of boreholes and the width of the cracks in Section 2.2.2 (Figure 13), the width of the cracks before mining is $0-20 \mathrm{~mm}$, most of them less than $10 \mathrm{~mm}$, and the width of the cracks after mining is $2 \sim 42 \mathrm{~mm}$, most of them between 15 and $20 \mathrm{~mm}$. After mining, the crack width and the number of cracks increase as a whole, which indicates that the fracture of the rock layer needs bulking space. At the same time, as shown in Figure 8, the number of cracks increases with the increase of the borehole depth, and then decreases. In the process of overburden breaking-collapse-compaction, the compressive stress is inversely proportional to its height and the residual bulking coefficient of the broken rock formation is low-high-low, which satisfies the relationship between the compressive stress and the residual bulking coefficient in equation (16).

By statistically analyzing the average crack widths of the soft and hard rock layers in different depths of the borehole, the histogram is drawn (Figure 14), and in the detected fractures in the soft and hard rock layers, the average crack width of the soft rock formation is $2.8 \mathrm{~mm}$ smaller than that of the hard rock. In that way, when the borehole depth is $45-60 \mathrm{~m}$, the difference of the average crack width of the soft and hard rock layers is $2 \mathrm{~mm}$. That is to say, the relatively low-pressure stress zone is located in the relatively high-position rock layer with small space allowable for expansion and no complete breaking and may not consider temporarily the influence of stress on the fracture of soft and hard rock layers. This indicates that the spatial constraint condition of hard rock stratum is smaller than that of soft rock stratum, which is in accordance with the space expansion constraints of hard and soft rock strata in equations (7) and (10).

\section{Discussions}

4.1. Accuracy Analysis. In order to verify the calculation accuracy of the method, based on the parameters such as mining 


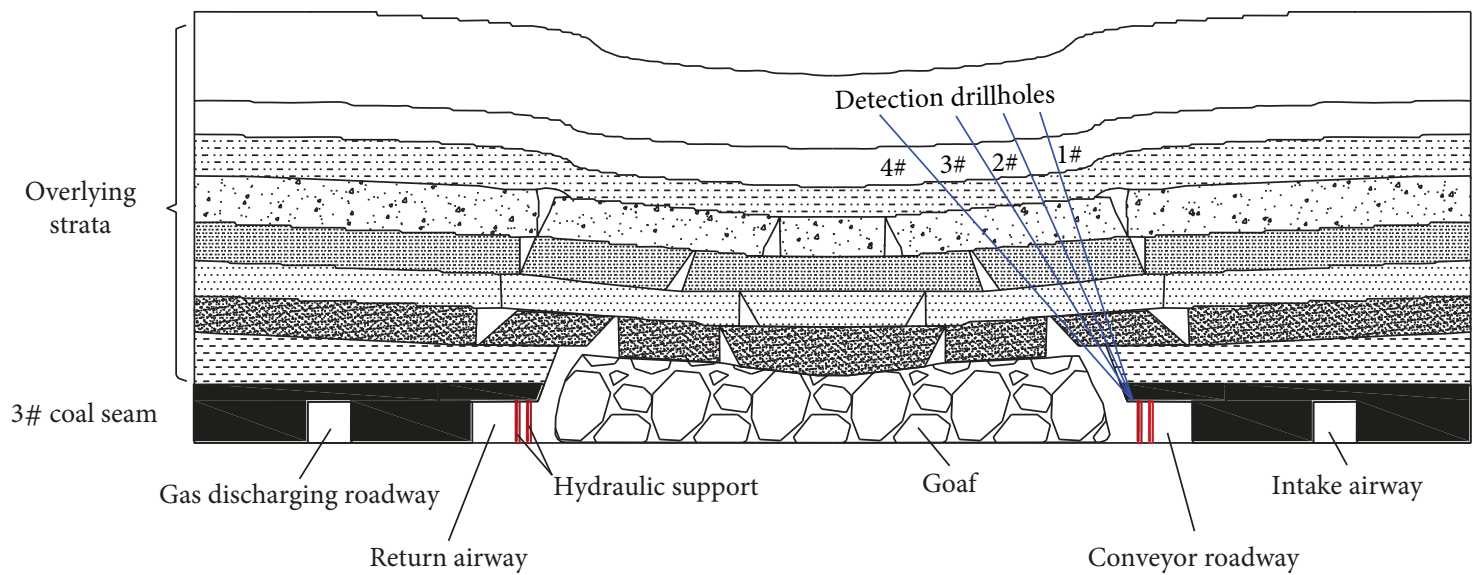

FIgURE 7: Schematic diagram showing endoscopic detection drilling-boreholes designed in N1102 working face.

TABle 4: Construction parameters of endoscopic detection drilling-boreholes.

\begin{tabular}{lcccc}
\hline Number & $\begin{array}{c}\text { Inclination } \\
\left({ }^{\circ}\right)\end{array}$ & $\begin{array}{c}\text { Azimuth } \\
\left({ }^{\circ}\right)\end{array}$ & $\begin{array}{c}\text { Aperture } \\
(\mathrm{mm})\end{array}$ & $\begin{array}{c}\text { Depth } \\
(\mathrm{m})\end{array}$ \\
\hline 1 & 70 & 270 & 113 & 96 \\
2 & 63 & 270 & 113 & 101 \\
3 & 55 & 270 & 113 & 110 \\
4 & 45 & 270 & 113 & 127 \\
\hline
\end{tabular}

height, buried depth, oblique length, advancing speed, and roof lithology of the N1102 working face in Yuwu coal mine, three representative theoretical methods for the height of overburden damage in coal seam mining were selected for calculation. That is, the empirical formula method proposed by the "three down" procedure, the key layer theory, and the multifactor fitting formula method of mining fracture zone. Through the comparative analysis of the above three methods and the error between the method and the measured overburden damage height, it further analyzed the method accuracy and reliability:

(1) The empirical formula from the "three down" procedure for mining fracture zone height is shown in Table 6 ( $M$ is mining height) [7]; the uniaxial strength of the rock is used to distinguish the type of overburden in the "three down" procedure. However, in order to avoid the statistical determination of the uniaxial compressive strength of the overburden, $\mathrm{Hu}$ et al. proposed a hard rock scale factor $b$ to classify the overburden type [15], which can simultaneously reflect uniaxial compressive strength and combined structural characteristics of overburden strata. As shown in formula (17), where $M$ is the mining height and $\sum h$ is the cumulative thickness of the hard rock formation in the estimated fracture zone height range (according to engineering experience, the value is generally 15 to 20 times higher than $\sum h$ ), $b \epsilon(0,1)$, as $b=0$, the overburden is an extremely weak type, as $b=1$, the overburden is a hard type, and as $0<b<1$, the overburden type is between weak and hard. The proportion of mudstone to sandy mudstone with the distance of $133 \mathrm{~m}$ to the roof of no. 3 coal seam of Yuwu coal mine is $56.63 \%$. It can be judged that the lithology of the roof is medium-hard and the average value of the damage height is $46.05 \mathrm{~m}$ according to the formula

$$
b=\frac{\sum h}{(15 \sim 20) M} .
$$

(2) Based on the analysis in Section 2.1 of this paper, the key layer 2 is broken and the key layer 3 is not broken. Therefore, it can be concluded that the height of the overburden damage of the working face is the height of the top layer of the $3 \#$ coal seam under the key layer 3, namely, $75.33 \mathrm{~m}$

(3) According to $\mathrm{Hu}$ et al.'s proposed multifactor fitting formula [15] for the mining fracture zone height, as shown in equation (18), $M, b, l, s$, and $v$ denote working face height $(\mathrm{m})$, roof hard rock lithologic proportion coefficient (\%), oblique length (m), mining depth $(\mathrm{m})$, and propulsion speed $(\mathrm{m} / \mathrm{d})$, respectively. The relevant parameter data for finishing the N1102 working face of Yuwu Coal Industry is presented in Table 7. The damage height of overburden rock in the working face can be $60.83 \mathrm{~m}$ by substituting parameter into formula (12)

$$
\begin{aligned}
H_{\mathrm{f}}= & 3.41 M+27.12 b+1.85 \ln l+0.11 \\
& \times \exp (5.35-426.24 / s)+0.64 v+6.11 .
\end{aligned}
$$

Comparing the above three methods and the error between our proposed method and the measured overburden damage height (Table 8), it can be seen from Table 7 that the error of the overburden damage height and the measured value of the N1102 working face calculated by this method is only $3.78 \%$, which is in allowable engineering error range. This is $10.8 \%$ lower than the error of the "three down" procedure, mainly because the coefficient selection in the empirical 


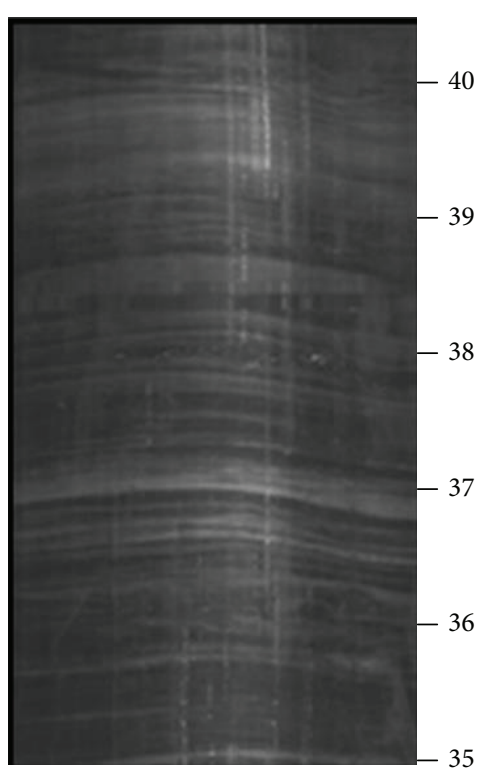

(a) Before mining

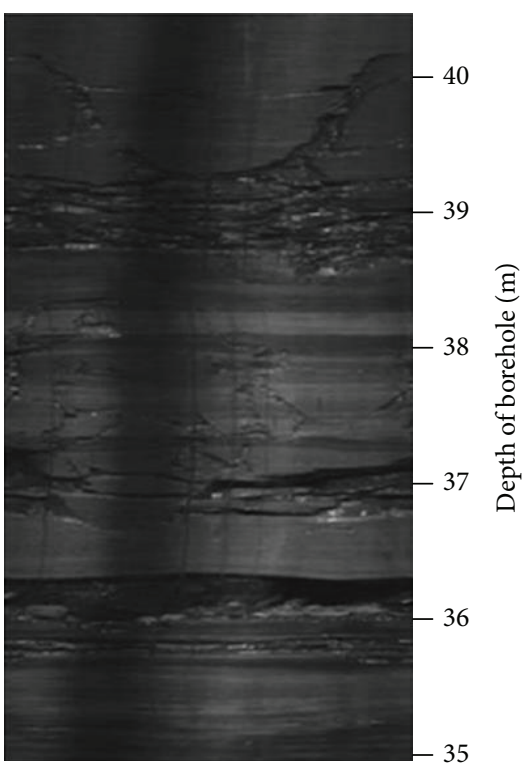

(b) After mining

Figure 8: Fracture distribution of borehole before and after mining.

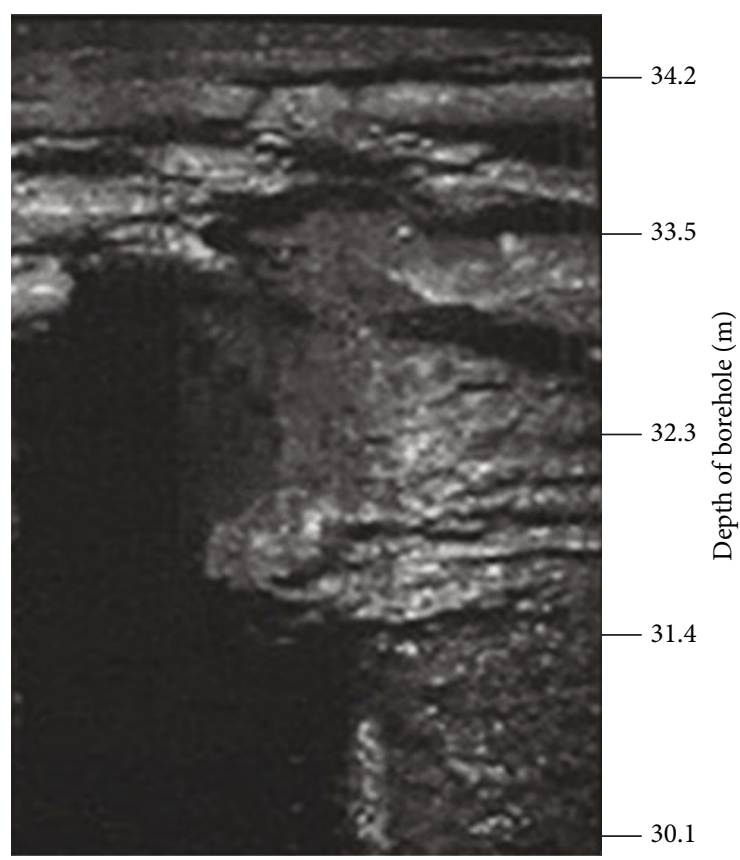

FIgURE 9: Development conditions of caving zone top.

formula in the "three down" procedure is based on the statistics of the entire North China region but the Lu'an mining area is only one of them with weak pertinence; the calculation error is $10.01 \%$ and $37.13 \%$ lower than the key layer theory method and the multifactor fitting formula method, because the key layer theory and the multifactor formula method are based on hard rock fracture analysis, with less consideration of soft rock layers which make suppression on the development of mining fissures. On the other hand, the height of bulking space beneath the overburden strata also plays an important role in the development of the height of mining

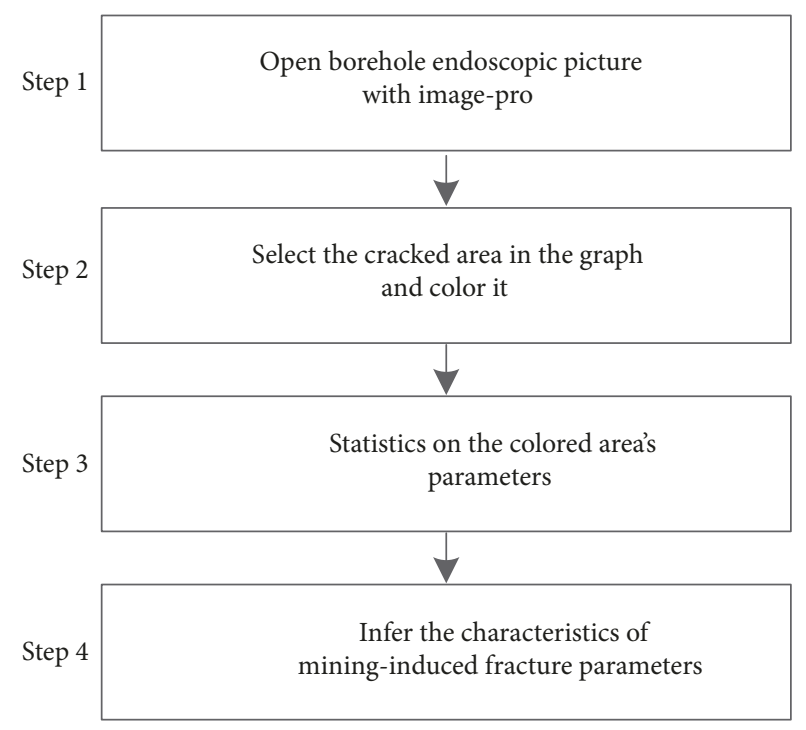

FIGURE 10: The analysis process of borehole endoscopic images using Image-Pro software.

fissure, which directly leads to the calculation results higher than the actual measurement, with a large error. The method proposed in this paper fully considered the comprehensive influence of coal mining height, working face length, key layer location, bulking space beneath rock mass, rock lithology, and breaking mode, and it avoided the inaccurate calculation of overburden damage height due to plastic failure of soft rock layer and pressure, later closure, and shrinkage in the bulking space beneath rock formation.

4.2. Principle of Selection of Tensile Strength. Due to the sedimentary environment of coal-bearing strata in different mining areas and the mineral composition, mesostructure (particle size and shape, intergranular connection, and 
TABle 5: Fracture numbers with different borehole depths before and after mining.

\begin{tabular}{lcc}
\hline $\begin{array}{l}\text { Different borehole } \\
\text { depth range }(\mathrm{m})\end{array}$ & \multicolumn{2}{c}{ Fracture number (bars) } \\
Before mining & After mining \\
\hline $0 \sim 10$ & 0 & 2 \\
$10 \sim 20$ & 6 & 21 \\
$20 \sim 30$ & 9 & 32 \\
$30 \sim 40$ & 6 & 38 \\
$40 \sim 50$ & 4 & 33 \\
$50 \sim 60$ & 5 & 21 \\
$60 \sim 70$ & 4 & 9 \\
$70 \sim 80$ & 1 & 6 \\
\hline
\end{tabular}

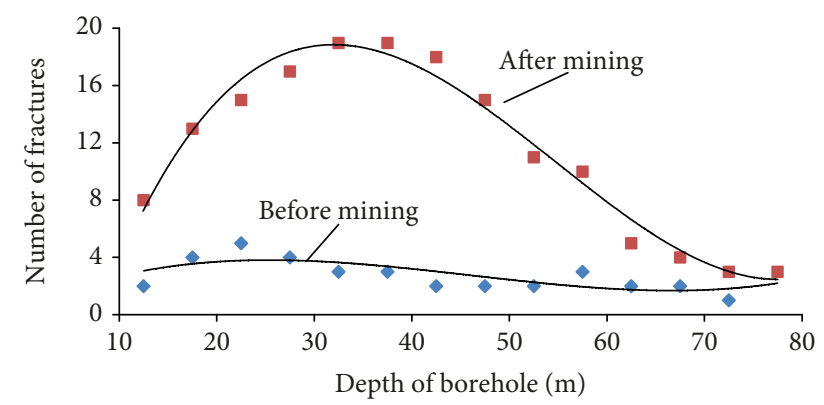

FIGURE 11: Relationship curves between borehole depth and fractures' quantity before and after mining.

microstructure surface), density, and degree of cementation of each rock layer lead to great difference in parameters such as tensile strength and compressive strength related to the overlying strata of coal seams in each mining area. At present, in the selection of rock tensile strength for the fracture mechanics analysis of each rock layer, the selected rock tensile strength is usually referred to the rock physics and mechanical parameter table [42] listed in the rock mechanics book based on a large number of national experimental data statistics, but they cannot accurately represent the physical and mechanical parameters of each rock formation in a mining area. Therefore, when applying the method proposed in this paper to calculate the damage height of mining overburden, the rock tensile strength values selected by formulas (7) and (11) need to be tested for rock mechanics parameters of each layer in rock stratum in the study area. The tensile strength of the rock selected in Section 2 in this paper comes from the experimental results of rock mechanics parameters of each rock stratum of the 3 \# coal seam overburden carried out by Wang in Yu'an coal mine, see Table 9 [37].

4.3. Applicable Conditions of Our Proposed Method. Because the rock fracture analysis of this method was based on the analysis of near horizontal coal seam mining conditions (coal dip angle $<5^{\circ}$ ), the self-gravity of overlying strata was a very small component in the dip direction of the rock stratum, but in the vertical direction of the rock stratum it can be approximated as the whole overburden gravity. The failure of rock strata is mainly rupture; however, for the mining conditions of gently inclined and steeply inclined coal seams, the vertical direction of overburden strata is the gravity of the overlying strata $\times \sin \alpha$ ( $\alpha$ is the dip angle of coal seam) and the direction of the overburden strata is overburden gravity $\times \cos \alpha$. Because there were different sliding friction coefficients between the rock layers, when the dip angle of the coal seam reaches a certain angle as well as the sliding force component in the dip direction of the overburden strata tends to be large enough, the rock strata tend to have sliding failure. At this time, the main failure type of the overburden strata was sliding failure and the failure is defined as failure of a composite type of sliding and rupture.

Due to the different internal friction angles for different rock layers, the rock layers in the non-near-level coal seam mining were greatly affected by the sliding between the strata. The failure mode of the rock stratum was not dominated by laminar failure. Whether it can be simplified as mechanical analysis of the plate girder model needs further study. In addition, the control of the geological structure, subsidence column, and water-rich conditions of the overburden should also be considered. Geological structure not only affects the thickness and inclination of the coal seam but also controls the stress environment, the thickness, inclination, and strength of the overburden strata. Collapse column directly affects the rock strength and the upward connectivity of mining-induced fracture, and it is also easy to mislead its detection and identification. The rock undergoes expansion and softening in the presence of a strong aquifer and reduces its mechanical strength. Due to the above factors, the stress unevenness and bearing characteristics of the rock strata would be changed. The residual bulking characteristics of the overburden strata after coal seam mining should be more complicated. A large error may occur in the calculation.

\section{Conclusions}

Based on the mechanical analysis of the fractures of different lithologic rocks in the overburden and the influencing factors of the residual bulking characteristics after breaking, this paper introduced fracture mechanics of the soft rock and the spatial constraints of the broken rock mass to construct a soft and hard rock fracture model. The selection principle of parameters such as tensile strength and residual bulking coefficient of rock in this method was established, which effectively eliminated the limitation of the fracture mechanics analysis method without consideration of soft rock layer and fixed the deviation of calculation result of overburden damage height caused by constant rock residual bulking coefficient. Through the application in Yuwu coal mine, the following conclusions were drawn:

(1) The quantitative criteria of soft and hard rock in the calculation of overburden damage height were given, and the fracture models of soft and hard rock layers were constructed. It proposed the calculation formulas of the breaking mechanical conditions and residual bulking coefficient: $K_{p}{ }^{\prime}=A \ln (x+0.027 H+$ $B \ln x+C \ln 0.027 H+D)$. It establishes a procedure of judging the damage height of soft and hard rock 


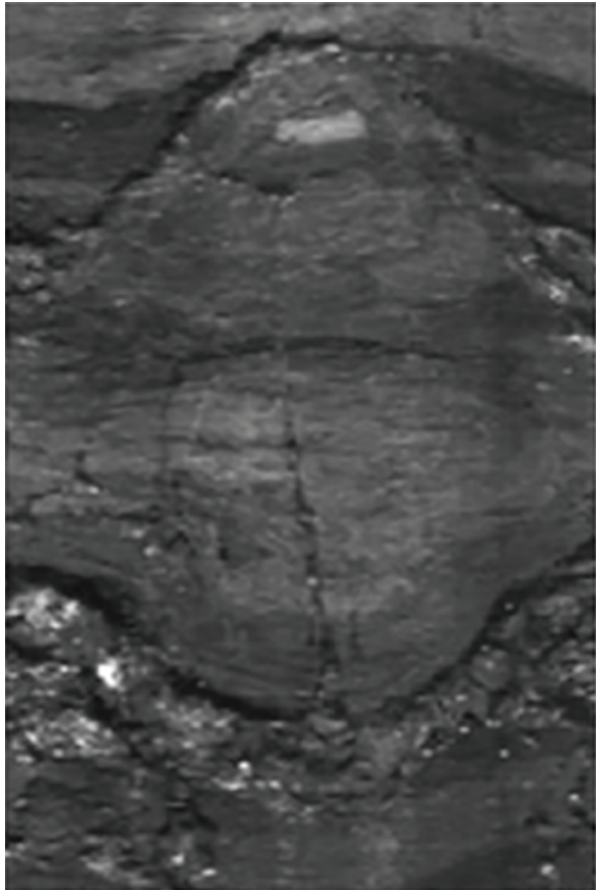

(a) Soft rock

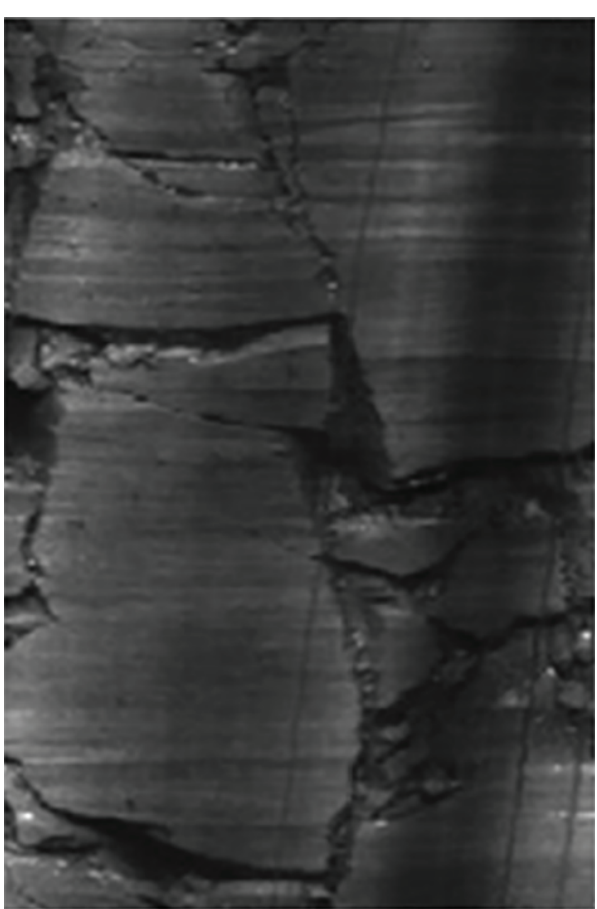

(b) Hard rock

FIGURE 12: Fracture distribution characteristics between soft and hard rocks after mining.

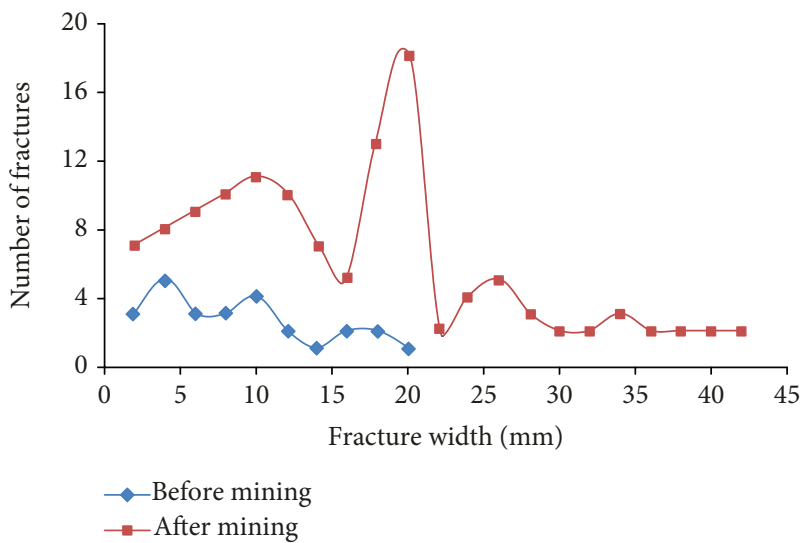

FIGURE 13: The variation of the number of cracks with the width of the fracture before and after mining.

interaction structure in overburden and calculated that the overburden damage height of the N1102 fully mechanized caving face in Yuwu coal mine was $51.44 \mathrm{~m}$; it was examined by the on-site drilling TV method, with a result of $53.46 \mathrm{~m}$, a deviation of only $2.02 \mathrm{~m}$, and the accuracy was about $96.22 \%$, greater than the calculation accuracy of the conventional three theoretical methods. According to the conditions of overlying rock in soft and hard rock interaction structure, the method proposed in this study fully considered the influence of the soft rock layer fracture mode and its residual bulking characteristics on overburden fracture development and improved the calculation accuracy of overburden damage height

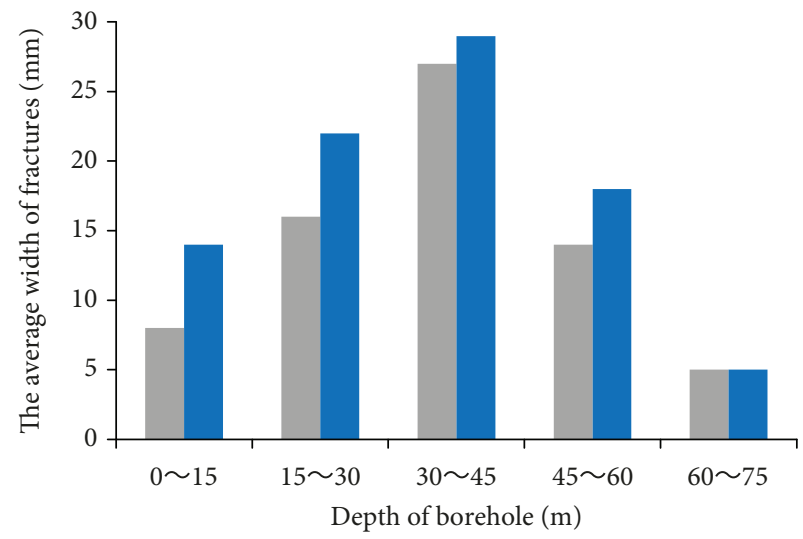

Soft rock

- Hard rock

FIgURE 14: Histograms of the average fracture width of soft and hard rocks with different borehole depths.

TABLE 6: Empirical formula from "three down" procedure [7].

\begin{tabular}{lc}
\hline UCS of rock $(\mathrm{MPa})$ & Calculation formula $(\mathrm{m})$ \\
\hline Hard $(40-80)$ & $H_{\mathrm{f}}=\frac{100 \sum M}{1.2 \sum M+2.0} \pm 8.9$ \\
Medium-hard $(20-40)$ & $H_{\mathrm{f}}=\frac{100 \sum M}{1.6 \sum M+3.6} \pm 5.6$ \\
Weak $(10-20)$ & $H_{\mathrm{f}}=\frac{100 \sum M}{3.1 \sum M+5.0} \pm 4.0$ \\
Extremely weak $(<10)$ & $H_{\mathrm{f}}=\frac{100 \sum M}{5.0 \sum M+8.0} \pm 3.0$ \\
\hline
\end{tabular}


TABLE 7: Influence parameter list of overlying stratum failure height in N1102 working face.

\begin{tabular}{lcccccc}
\hline Working face & Mining height $(\mathrm{m})$ & $\begin{array}{c}\text { Hard rock lithology } \\
\text { ratio }(\%)\end{array}$ & $\begin{array}{c}\text { Tendency } \\
\text { length }(\mathrm{m})\end{array}$ & $\begin{array}{c}\text { Buried } \\
\text { depth }(\mathrm{m})\end{array}$ & $\begin{array}{c}\text { Advancing } \\
\text { speed }(\mathrm{m} / \mathrm{d})\end{array}$ & $\begin{array}{c}\text { Overlying strata damage } \\
\text { height }(\mathrm{m})\end{array}$ \\
\hline N1102 & 6.3 & 56.63 & 280 & $420 \mathrm{~m}$ & 5 & 64.83 \\
\hline
\end{tabular}

TABLE 8: Overlying stratum damage height calculation accuracy by 4 methods.

\begin{tabular}{|c|c|c|c|c|c|c|c|c|c|}
\hline \multirow{2}{*}{$\begin{array}{l}\text { Working } \\
\text { face }\end{array}$} & \multirow{2}{*}{$\begin{array}{c}\text { Actual } \\
\text { measurement } \\
\text { of overburden } \\
\text { damage height }\end{array}$} & \multicolumn{2}{|c|}{ “Three down" procedure } & \multicolumn{2}{|c|}{$\begin{array}{l}\text { Fitting formula } \\
\text { with multifactors }\end{array}$} & \multicolumn{2}{|c|}{ Key layer theory } & \multicolumn{2}{|c|}{ Method in this paper } \\
\hline & & Calculation & $\begin{array}{c}\text { Relative } \\
\text { error }\end{array}$ & Calculation & $\begin{array}{c}\text { Relative } \\
\text { error }\end{array}$ & Calculation & $\begin{array}{c}\text { Relative } \\
\text { error }\end{array}$ & Calculation & $\begin{array}{c}\text { Relative } \\
\text { error }\end{array}$ \\
\hline N1102 & $53.46 \mathrm{~m}$ & $46.05 \mathrm{~m}$ & $13.86 \%$ & $60.83 \mathrm{~m}$ & $13.79 \%$ & $75.33 \mathrm{~m}$ & $40.91 \%$ & $51.44 \mathrm{~m}$ & $3.78 \%$ \\
\hline
\end{tabular}

TABLE 9: Rock mechanical parameter measurements of overlying strata in Yuwu coal mine [37].

\begin{tabular}{lcc}
\hline Rock formation name & $\begin{array}{c}\text { Tensile strength } \\
(\mathrm{MPa})\end{array}$ & $\begin{array}{c}\text { Compressive } \\
\text { strength (MPa) }\end{array}$ \\
\hline K8 sandstone & $\frac{6.56 \sim 8.71}{8.01}$ & $\frac{87.8 \sim 93.5}{91.3}$ \\
Coarse sandstone & $\frac{3.24 \sim 6.11}{5.12}$ & $\frac{46.7 \sim 59.8}{54.6}$ \\
Medium sandstone & $\frac{5.78 \sim 9.29}{7.63}$ & $\frac{80.1 \sim 100.9}{92.4}$ \\
Fine sandstone & $\frac{6.14 \sim 8.81}{7.34}$ & $\frac{76.5 \sim 99.6}{85.7}$ \\
Siltstone & $\frac{3.52 \sim 5.98}{5.24}$ & $\frac{50.4 \sim 65.8}{58.9}$ \\
Sandy mudstone & $\frac{3.63 \sim 6.14}{5.03}$ & $\frac{35.4 \sim 53.2}{43.6}$ \\
Mudstone & $\underline{1.04 \sim 1.14}$ & $\frac{30.2 \sim 39.9}{36.4}$ \\
\hline
\end{tabular}

(2) Based on the imaging analysis of borehole TV, it was concluded that there was no obvious fracture in the fracture interval of the soft rock layer and the low-angle fracture was dominant; the fractured cracks of the hard rock layer had obvious fractures and rich high-angle fractures, and its fracture width $>$ soft rock fractured crack width. This indicated that the fracture modes of soft rock and hard rock were mainly tensile failure and tensile shear failure, which indirectly verified the correctness of the fracture mechanics model of soft and hard rock layers constructed in this paper; the soft rock layer was easily compacted after breaking, and the relatively high requirement for bulking space also indicated that the soft rock had a restraining effect on the height of the overburden damage

(3) It is pointed out that the selection principle of rock tensile strength and compressive strength in this method was based on the rock mechanics experiment of overlying strata in the study area, given that the method is applicable to the calculation of overburden damage height in near horizontal coal seam mining
The applicability of the proposed method under the conditions of gently inclined and steeply inclined coal seam mining needs further study. The subsequent mechanism of the influence of coal seam dip angle on overburden failure can be systematically studied. The force distribution, failure mode, and breaking structure of different dip angle overlying strata should be studied. By comprehensively considering the influence of geological structure, subsided column, and water-rich conditions of the overburden, the in-depth systematic study of its mechanical properties is conducive to broadening the scope of application of this method. This has important guiding significance for optimizing the design of gas drainage boreholes in the overburden fracture zone of different occurrence conditions of coal seams and the evaluation method of water inrush risk in coal seam mining.

\section{Data Availability}

The data used to support the findings of this study are available from the corresponding author upon request.

\section{Conflicts of Interest}

The authors declare that they have no conflicts of interest.

\section{Acknowledgments}

This study was financially supported by the National Key Research and Development Program of China under grant no. 2017YFC0804206-002 and National Science and Technology Major Project of the Ministry of Science and Technology of China during "13th Five-Year Plan" under grant no. 2016ZX05067005-005. The authors gratefully appreciate Prof. Shaowu Fan, Zhengchao Chen, and Yongshun Han for their assistance on the final language editing and the whole logical structure in this paper.

\section{References}

[1] Z. P. Meng, X. C. Shi, and G. Q. Li, "Deformation, failure and permeability of coal-bearing strata during longwall mining," Engineering Geology, vol. 208, pp. 69-80, 2016. 
[2] D. P. Adhikary and H. Guo, "Modelling of longwall mining-induced strata permeability change," Rock Mechanics and Rock Engineering, vol. 48, no. 1, pp. 345-359, 2015.

[3] A. Kayabasi, N. Yesiloglu-Gultekin, and C. Gokceoglu, "Use of non-linear prediction tools to assess rock mass permeability using various discontinuity parameters," Engineering Geology, vol. 185, pp. 1-9, 2015.

[4] A. P. Singh, P. K. Gupta, and M. Khandelwal, "Prediction of sea water intrusion for mining activity in close precincts of sea shore," SpringerPlus, vol. 2, no. 1, pp. 417-426, 2013.

[5] R. Álvarez, A. Ordóñez, E. de Miguel, and C. Loredo, "Prediction of the flooding of a mining reservoir in NW Spain," Journal of Environmental Management, vol. 184, pp. 219-228, 2016.

[6] T. Q. Liu, Ground Movement and Overburden Failure Law of Coal Mine and Its Application, China Coal Industry Press, Beijing, China, 1981.

[7] National Coal Industry Bureau of China, Rules for Coal Pillars Design of Main Shafts and Coal Mining under Buildings, Water Bodies and Railways, China Coal Industry Press, Beijing, China, 2017.

[8] M. J. Qian, P. W. Shi, and J. L. Xu, Mining Pressure and Strata Control, China University of Mining and Technology Press, Xuzhou, China, 2010.

[9] J. L. Xu, W. B. Zhu, and X. Z. Wang, "New method to predict the height of fractured water-conducting zone by location of key strata," Journal of China Coal Society, vol. 37, pp. 762769, 2012.

[10] J. P. Zuo, Y. J. Sun, and M. J. Qian, "Movement mechanism and analogous hyperbola model of overlying strata with thick alluvium," Journal of China Coal Society, vol. 42, pp. 13721379, 2017.

[11] G. S. P. Singh and U. K. Singh, "Prediction of caving behavior of strata and optimum rating of hydraulic powered support for longwall workings," International Journal of Rock Mechanics and Mining Sciences, vol. 47, no. 1, pp. 1-16, 2010.

[12] M. Abbas, F. P. Hassani, and M. Y. Nasiri, "Prediction of the height of destressed zone above the mined panel roof in longwall coal mining," International Journal of Coal Geology, vol. 98, pp. 62-72, 2012.

[13] S. G. Li, H. F. Lin, and P. X. Zhao, "Dynamic evolution of mining fissure elliptic paraboloid zone and extraction coal and gas," Journal of China Coal Society, vol. 39, pp. 1455-1462, 2014.

[14] J. P. Xu, K. Bian, and J. L. Cheng, "Study of water-flow fracture zone height based on critical value of rock angular displacement," Journal of China University of Mining and Technology, vol. 40, pp. 536-539, 2011.

[15] X. J. Hu, W. P. Li, and D. T. Cao, "Index of multiple factors and expected height of fully mechanized water flowing fractured zone," Journal of China Coal Society, vol. 37, pp. 613-620, 2012.

[16] M. Ju, X. Li, Q. Yao, S. Liu, S. Liang, and X. Wang, "Effect of sand grain size on simulated mining-induced overburden failure in physical model tests," Engineering Geology, vol. 226, pp. 93-106, 2017.

[17] D. Zhang, W. Sui, and J. Liu, "Overburden failure associated with mining coal seams in close proximity in ascending and descending sequences under a large water body," Mine Water and the Environment, vol. 37, no. 2, pp. 322-335, 2018.

[18] W. Sui, Y. Hang, L. Ma et al., "Interactions of overburden failure zones due to multiple-seam mining using longwall caving," Bulletin of Engineering Geology and the Environment, vol. 74, no. 3, pp. 1019-1035, 2015.

[19] J. L. Xu, X. Z. Wang, and W. T. Liu, "Effects of primary key stratum location on height of water flowing fracture zone," Chinese Journal of Rock Mechanics and Engineering, vol. 28, pp. 380-385, 2009.

[20] D. S. Zhao, F. Chen, and Z. C. Wang, "The experimental study on the failure of soft over burden in mining of thick coal seam," Journal of Guangxi University, vol. 36, pp. 177-181, 2012.

[21] F. Du and H. B. Bai, "Mechanism research of overlying strata activity with fully mechanized caving in thin bedrock with thick alluvium," Journal of China Coal Society, vol. 37, pp. 177-181, 2012.

[22] P. K. Mandal, R. Singh, J. Maiti, A. K. Singh, R. Kumar, and A. Sinha, "Underpinning-based simultaneous extraction of contiguous sections of a thick coal seam under weak and laminated parting," International Journal of Rock Mechanics and Mining Sciences, vol. 45, no. 1, pp. 11-28, 2008.

[23] M. D. R. Islam, D. Hayashi, and A. B. M. Kamruzzaman, "Finite element modeling of stress distributions and problems for multi-slice longwall mining in Bangladesh, with special reference to the Barapukuria coal mine," International Journal of Coal Geology, vol. 78, no. 2, pp. 91-109, 2009.

[24] V. Vishal, P. G. Ranjith, and T. N. Singh, “An experimental investigation on behaviour of coal under fluid saturation, using acoustic emission," Journal of Natural Gas Science and Engineering, vol. 22, pp. 428-436, 2015.

[25] Y. J. Ma, Q. Wu, and Z. Y. Zhang, "Research on prediction of water conducted fissure height in roof of coal mining seam," Coal Science and Technology, vol. 36, pp. 59-62, 2008.

[26] X. G. Xia and Q. X. Huang, "Study on the dynamic height of caved zone based on porosity," Journal of Mining and Safety Engineering, vol. 31, pp. 18-26, 2014.

[27] J. F. Ju and J. L. Xu, "Structural characteristics of key strata and strata behaviour of a fully mechanized longwall face with $7.0 \mathrm{~m}$ height chocks," International Journal of Rock Mechanics and Mining Sciences, vol. 58, pp. 46-54, 2013.

[28] B. Unver and N. E. Yasitli, "Modelling of strata movement with a special reference to caving mechanism in thick seam coal mining," International Journal of Coal Geology, vol. 66, no. 4, pp. 227-252, 2006.

[29] J. L. Xu and M. G. Qian, "Method to distinguish key strata in overburden," Journal of China University of Mining and Technology, vol. 9, pp. 463-467, 2000.

[30] W. B. Xie, X. X. Chen, and B. S. Zheng, Numerical Simulation Research and Analysis about Mining Engineering Problems, China University of Mining and Technology Press, Xuzhou, China, 2005.

[31] Ministry of Water Resources of the People's Republic of China, B/T 50218-2014 Standard for Engineering Classification of Rock Mass, China Standard Press, Beijing, 2015.

[32] H. W. Zhang, Z. J. Zhu, and L. J. Huo, "Overburden failure height of superhigh seam by fully mechanized caving method," Journal of China Coal Society, vol. 39, pp. 816-821, 2014.

[33] J. Zhang, X. Y. Yu, and L. H. Cheng, "Failure mechanism of soil layer in long wall face intermission advance in shallow seam mining," Journal of Liaoning Technical University, vol. 27, pp. 801-804, 2008.

[34] C. D. Su, M. Gu, and X. Tang, "Experiment study of compaction characteristics of crushed stones from coal seam roof," 
Chinese Journal of Rock Mechanics and Engineering, vol. 31, pp. 18-26, 2012.

[35] D. G. Xiong, Z. M. Zhao, and C. D. Su, "Experimental study on effect of water-saturated state on mechanical properties of rock in coal measure strata," Chinese Journal of Rock Mechanics and Engineering, vol. 30, pp. 998-1006, 2011.

[36] G. L. Guo, X. X. Miao, and Z. N. Zhang, "Research on ruptured rock mass deformation characteristics of longwall goafs," Science Technology and Engineering, vol. 2, pp. 44-47, 2002.

[37] X. L. Wang, The Development Aapplication and Research on Height of Two Zones Overburden in the Fully Mechanized Mining, Henan Polytechnic University, Jiaozuo, China, 2013.

[38] H. P. Kang, L. P. Si, and B. Su, "Borehole observation methods in coal and rock mass and their applications," Journal of China Coal Society, vol. 35, pp. 1949-1956, 2010.

[39] Y. J. Zhang, H. X. Zhang, and P. P. Chen, "Visual exploration of distribution characteristic of fissure field of overburden and mining rock mass," Journal of China Coal Society, vol. 33, pp. 1216-1219, 2008.

[40] H. Wang, D. Zhang, X. Wang, and W. Zhang, "Visual exploration of the spatiotemporal evolution law of overburden failure and mining-induced fractures: a case study of the Wangialing coal mine in China," Minerals, vol. 7, no. 3, 2017.

[41] X. C. Shi, Study on Deformation-Failure of Overlying Strata Induced by Coal Mining and Its Permeability Assessment, China University of Mining \& Technology, Beijing, Beijing, 2016.

[42] Y. Chen, T. F. Huang, and E. R. Liu, Rock Physics, China University of Science and Technology Press, Hefei, 2009. 

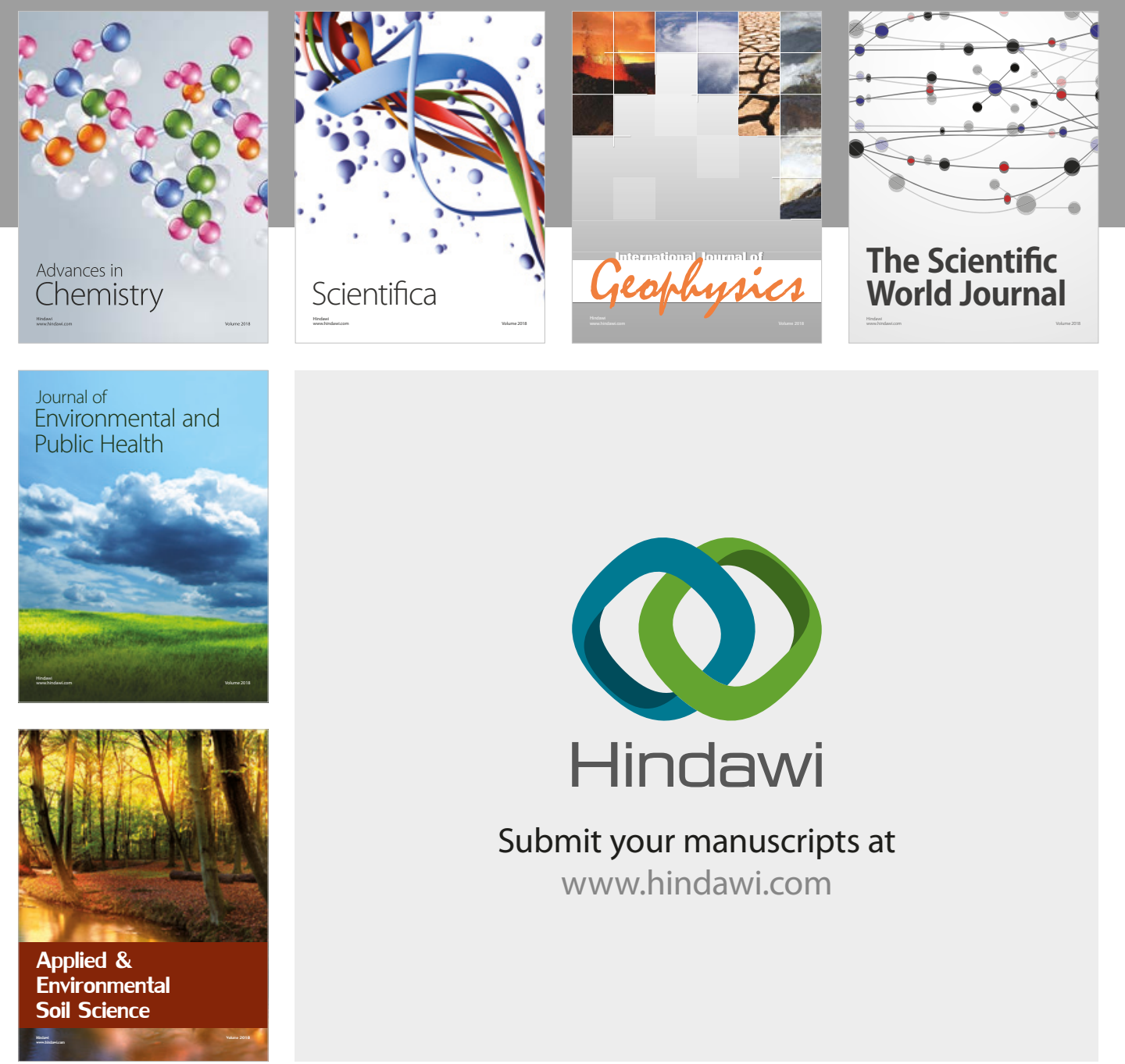

The Scientific

\section{World Journal}
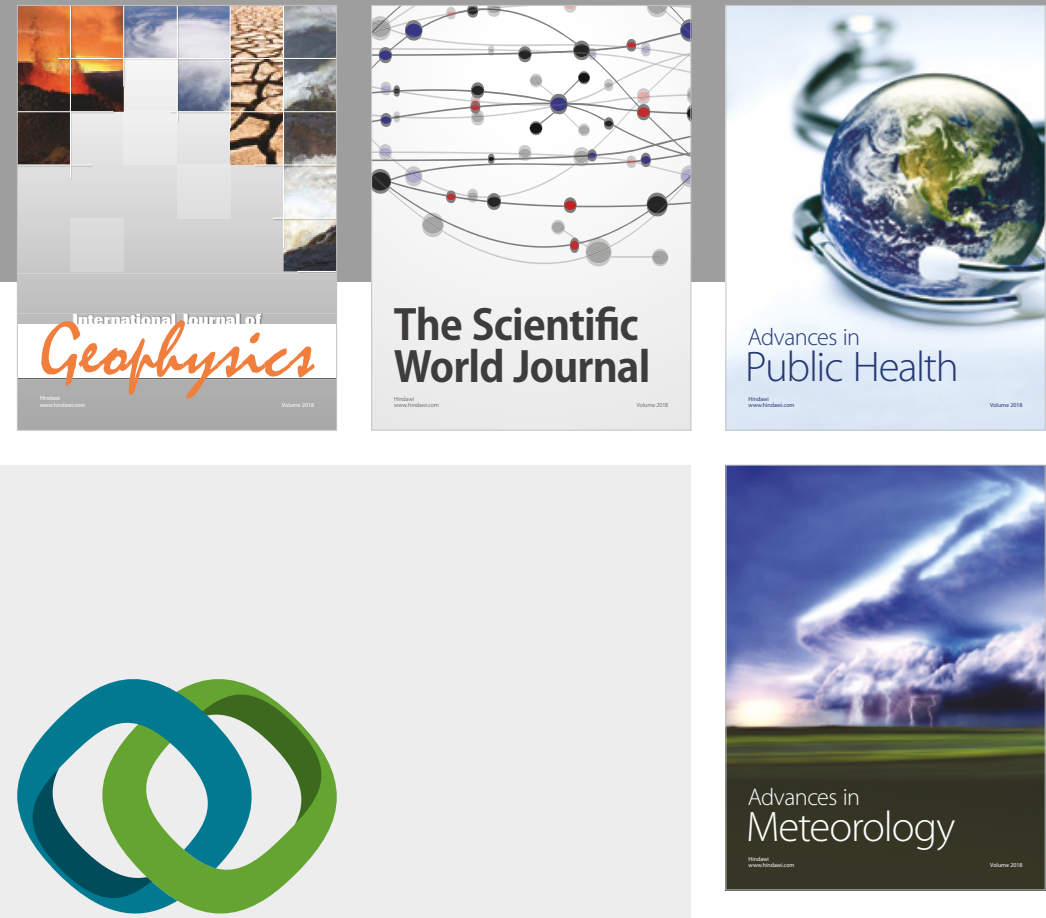

Advan

Public Health

\section{Hindawi}

Submit your manuscripts at

www.hindawi.com
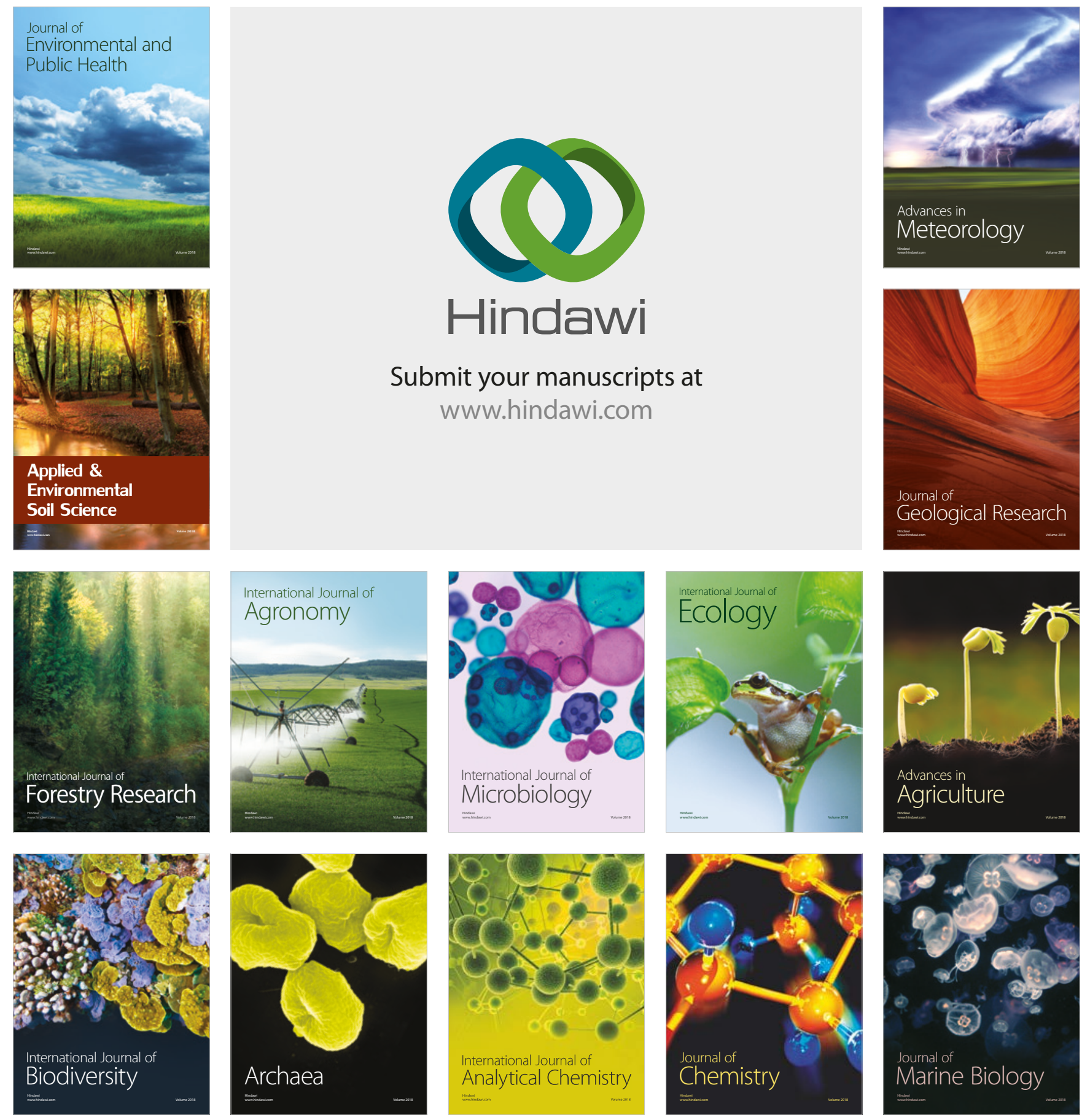